\title{
Pharmacological treatment of frontotemporal lobar degeneration: systematic review
}

\section{Tratamento farmacológico da degeneração lobar frontotemporal: revisão sistemática}

\author{
Maria da Glória Portugal,, ${ }^{1}$ Valeska Marinho, ${ }^{2}$ Jerson Laks ${ }^{1,3,4}$ \\ ${ }^{1}$ Centre for Alzheimer's Disease and Related Disorders, Institute of Psychiatry, Universidade Federal do Rio de Janeiro (UFRJ), Rio de Janeiro, \\ RJ, Brazil \\ ${ }^{2}$ Medical Manager GlaxoSmithKline (GSK) \\ ${ }^{3}$ Faculdade de Ciências Médicas, Universidade do Estado do Rio de Janeiro (UERJ), Rio de Janeiro, RJ, Brazil \\ ${ }^{4}$ Researcher 2, Conselho Nacional de Desenvolvimento Científico e Tecnológico (CNPq), Brazil
}

\begin{abstract}
Objective: To identify the therapeutic options available for treatment of cognitive and behavioral symptoms in frontotemporal lobar degeneration. Method: Systematic review using the descriptors "frontotemporal lobar degeneration" OR "frontotemporal dementia" OR "fronto-temporal dementia" OR "fronto-temporal degeneration" OR "Pick's disease" OR "Pick's atrophy" OR "semantic dementia" OR "progressive aphasia" AND "pharmacotherapy" OR "treatment" OR "efficacy" OR "effects" OR "management" was performed in the Medline and Lilacs databases. Selection criteria: Quality A - randomized clinical trials. Quality B open studies or reports of six or more cases. Quality C - reports of five or fewer cases. Two reviewers independently assessed the clinical studies. Information collected included diagnostic criteria used, sample size, duration, efficacy and tolerability measures used and results obtained. Results: From the 532 studies found, 29 complied with the inclusion criteria. All studies worked with a small sample, had short duration of treatment and used non-uniform measures in evaluating efficacy and tolerability. Studies showed disparate results with respect to behavior and cognition. Conclusion: There is still little, and poor, evidence available for treatment of frontotemporal lobar degeneration and studies with better methodological background are needed.
\end{abstract}

Descriptors: Frontotemporal dementia; Pick's disease; Therapeutics; Review; Frontotemporal lobar degeneration

\begin{abstract}
Resumo
Objetivo: Identificar as opçôes terapêuticas disponiveis para tratamento dos sintomas cognitivos e comportamentais da degeneração lobar frontotemporal. Método: Revisão sistemática utilizando os descritores "frontotemporal lobar degeneration OR frontotemporal dementia OR fronto-temporal dementia OR fronto-temporal degeneration OR Pick's disease OR Pick's atrophy OR semantic dementia OR progressive aphasia AND pharmacotherapy OR treatment OR efficacy OR effects OR management" nas bases Medline e Lilacs. Critérios de seleção: Qualidade A - Estudos clínicos randomizados. Qualidade B - Estudos abertos ou relatos de seis ou mais casos. Qualidade C Relatos de cinco ou menos casos. Dois revisores avaliaram independentemente os estudos clínicos. As informaçôes coletadas incluíram critérios de diagnóstico utilizados, número da amostra, duração, medidas de eficácia e tolerabilidade utilizadas e os resultados obtidos. Resultados: Encontraram-se 532 estudos e 29 preenchiam os critérios. Todos os estudos incluíam uma amostra pequena, com curta duração de tratamento, com utilização de medidas não uniformes na avaliação da eficácia e da tolerabilidade. O comportamento e a cognição apresentaram resultados díspares entre os estudos. Conclusão: São poucas as evidências disponiveis para tratamento da degeneração lobar frontotemporal e de qualidade insatisfatória, sendo necessários estudos com maior rigor metodológico.
\end{abstract}

Descritores: Demência frontotemporal; Doença de Pick; Terapêutica; Revisão; Degeneração lobar frontotemporal

\section{Introduction}

The clinical syndromes related to frontotemporal lobar degeneration (FTLD) are the second most common cause of pre-senile primary dementia. ${ }^{1}$ A recent Brazilian epidemiological study found a dementia prevalence of $7.1 \%$ in individuals over
65 years of age; FTLD was responsible for $2.6 \%$ of these cases, ${ }^{2}$ whereas worldwide prevalence rates range from $5-15$ per 100,000 persons. ${ }^{3-5}$ These disorders share some distinct characteristics which are mainly centered on behavioral, psychological and

\section{Correspondence}

Jerson Laks

Av. Copacabana, 749/802

22051-000 Rio de Janeiro, RJ, Brasil 
language symptoms. There are three distinct clinical variants considered according to the sites of the frontal neurodegeneration and clinical syndromes: behavioral-variant frontotemporal dementia, semantic dementia and progressive non-fluent aphasia. Behavioral-variant frontotemporal dementia is characterized by changes in behavior and personality associated with frontalpredominant cortical degeneration; semantic dementia is a syndrome characterized by progressive loss of knowledge about words and objects, combined with anterior temporal neuronal loss; and progressive non-fluent aphasia is characterized by progressive loss of language with difficulty in speaking, loss of grammar and motor speech deficits, together with left perisylvian cortical atrophy. ${ }^{6}$ FTLD can also overlap with the atypical parkinsonian disorders and with amyotrophic lateral sclerosis. ${ }^{6}$

Although the clinical criteria to diagnose FTLD are considered to be sensitive and reliable, it is still difficult in clinical practice to be sure about the differential diagnosis with other neurological and psychiatric disorders (such as bipolar disorder, schizophrenia, vascular dementia or Alzheimer's Disease) in part because of lack of biological markers to ascertain the disease. ${ }^{7-9}$ Some patients with the behavioral variant of FTLD are frequently misdiagnosed with a psychiatric disorder, most often schizophrenia, major depression or bipolar disorder. ${ }^{6}$

So far, the available pharmacological and rehabilitation strategies have not provided enough evidence of efficacy in this group of diseases. ${ }^{10}$ In fact, there is a dearth of data to guide the clinician on treatment strategies. This study aims to systematically review the evidence on the treatment options for the cognitive and behavioral symptoms in FTLD.

\section{Method}

The search strategy was designed so as to initially retrieve a large number of articles on the theme. Medline and Lilacs databases from $1990 / 01 / 01$ to $2009 / 12 / 31$ were examined and a manual search of the cited references and of specialized journals was also performed. We used the following descriptors: frontotemporal lobar degeneration OR frontotemporal dementia OR frontotemporal dementia OR fronto-temporal degeneration OR Pick's disease OR Pick's atrophy OR semantic dementia OR progressive aphasia AND pharmacotherapy OR treatment OR efficacy OR effects OR management.

\section{Study selection}

We included in this review intervention studies which provided clinical and objective measures of relevant outcomes. Intervention studies with non-pharmacological strategies were excluded.

Evaluation of the quality of the studies:

The quality of the studies was assessed according to the 2009 Updated Method Guidelines for Systematic Reviews in the Cochrane Back Review Group. ${ }^{11}$ The groups should be paired at baseline, objective measures of the presence and severity of symptoms should be recorded, the dropout number and rate at follow-up should be documented, as well as the presence of any adjunct therapy. The studies were therefore classified as Quality
A - randomized; Quality B - open studies or case reports with more than six patients; Quality C - case reports with fewer than five patients.

Two reviewers (VM, MGP) independently assessed the clinical trials, collecting data regarding the diagnostic criteria, sample number, duration of treatment, measures of efficacy and of tolerability, and results. The outcome measures for this systematized review were improvement in behavior and cognitive symptoms.

\section{Results}

The search strategy was able to retrieve 532 publications, and 29 studies fulfilled the inclusion criteria for this review. The other studies were excluded because they did not assess the therapeutic options for FTLD $(n=346)$, or because they were review articles on the subject $(\mathrm{n}=157)$.

A total of 390 patients participated in the 29 selected studies $($ mean $=13.45, \mathrm{SD}=14.45)$. The largest sample comprised 49 patients ${ }^{12}$ and seven studies were single-case reports. ${ }^{13-19}$

Nine studies did not define the subtype of FTLD analyzed $(\mathrm{n}=124)$. Among the studies that defined the FTLD subtypes, the behavioral variant was the most common $(n=202)$, followed by progressive non-fluent aphasia $(\mathrm{n}=38)$ and semantic dementia $(n=25)$. One case of amyotrophic lateral sclerosis with frontotemporal dementia was also analysed.

The diagnostic criteria for FTLD varied from study to study, since $37.9 \%$ used the Lund-Manchester criteria, $17.2 \%$ used the criteria by Neary et al. ${ }^{8} 20.7 \%$ used other criteria, and $31 \%$ did not describe which criteria were used.

Magnetic Resonance Imaging (MRI) was used in $44.8 \%$ of the studies and Computed Tomography (CT) in $10.3 \%$, but in $10.3 \%$ of the studies MRI or CT were not done in all cases. Single Photon Emission Computerized Tomography (SPECT) was performed in $31 \%$ of the studies, but in one study SPECT was done in only 2 of 3 cases. Positron Emission Tomography (PET) was the neuroimaging technique used in only $6.9 \%$ of the studies, whereas $20.7 \%$ of the studies did not say whether any neuroimaging was done. One case report (3.4\%) reported that the patient refused to submit to neuroimaging examinations. This review found that $24.1 \%$ of the studies performed either MRI plus SPECT, or MRI plus PET.

Most articles were open studies with case series or single case reports. There were six quality A randomized trials, 12 quality $\mathrm{B}$, and 11 quality $\mathrm{C}$. Tables 1, 2 and 3 depict their main characteristics.

Of the two quality A studies ${ }^{20,21}$ which assessed Paroxetine, one found a statistically significant cognitive worsening whereas the other noticed a statistically significant improvement in behavior. ${ }^{22}$ One study that assessed acetylcholinesterase inhibitors observed a significant cognitive improvement. ${ }^{22}$ One quality A study which assessed Trazodone observed a significant improvement in behavior, whereas cognition showed no significant change. ${ }^{23}$ Likewise, another quality A study saw significant improvement in apathy and disinhibition with Dextroamphetamine ${ }^{24}$ whereas in 


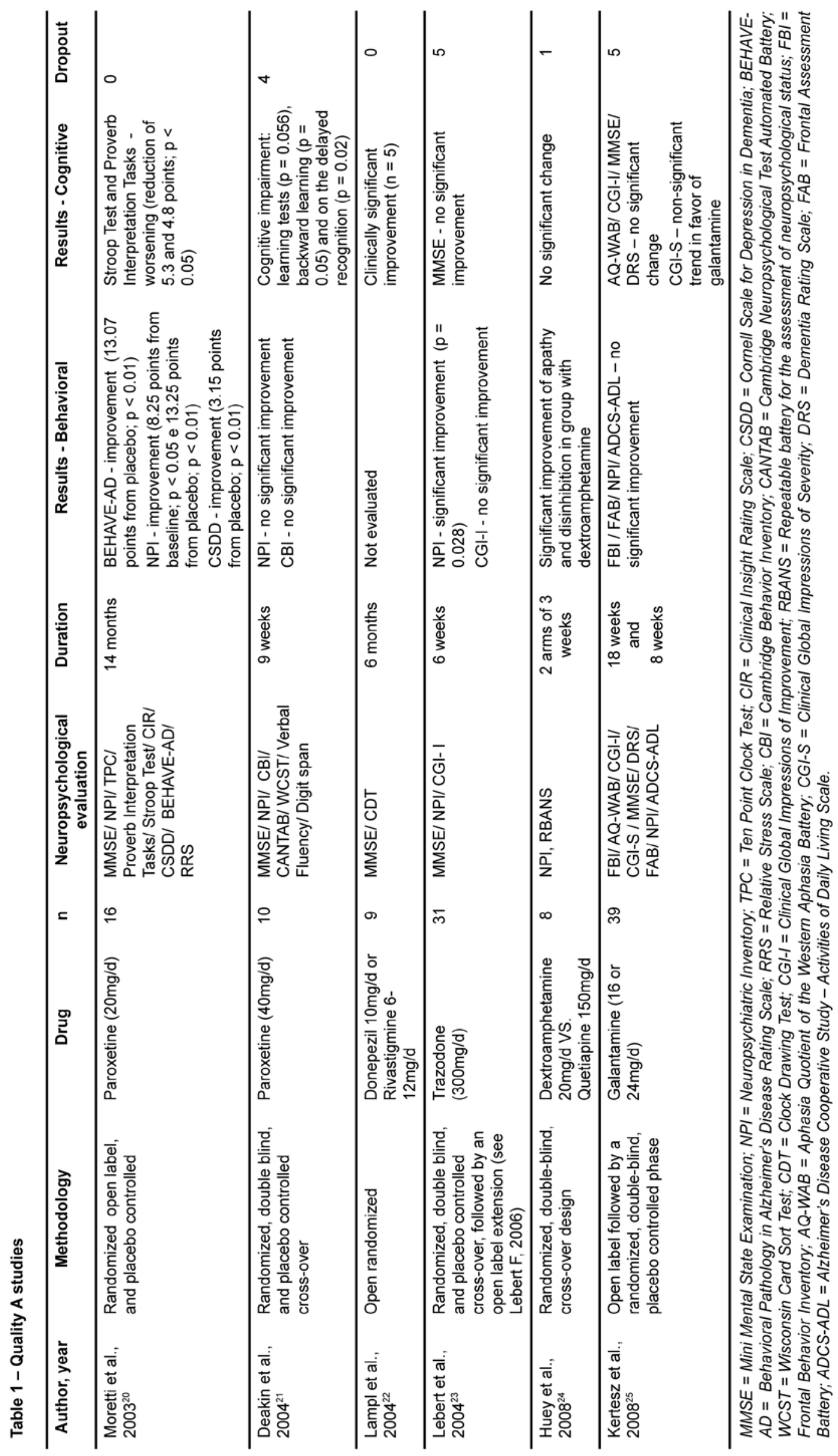




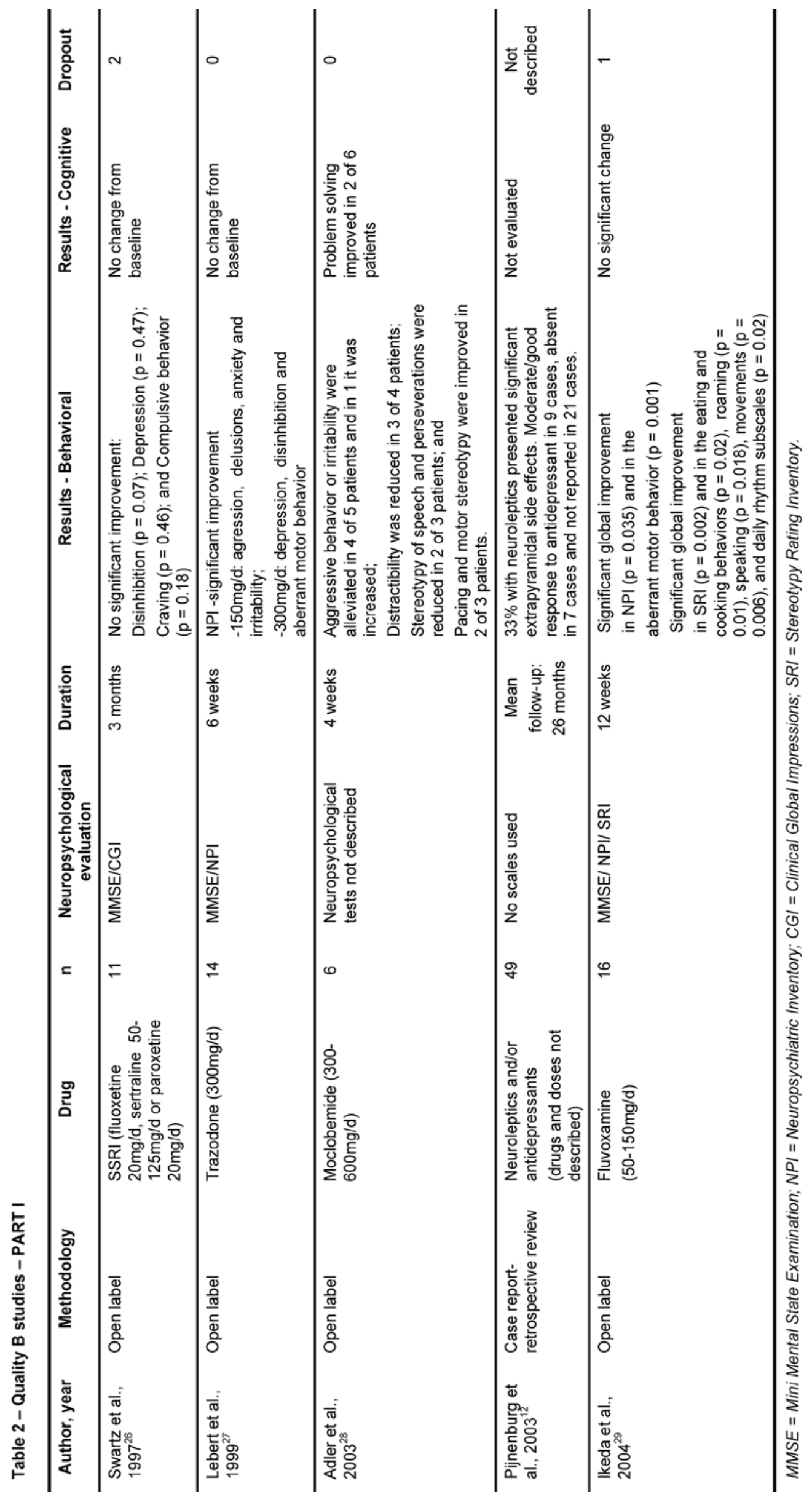




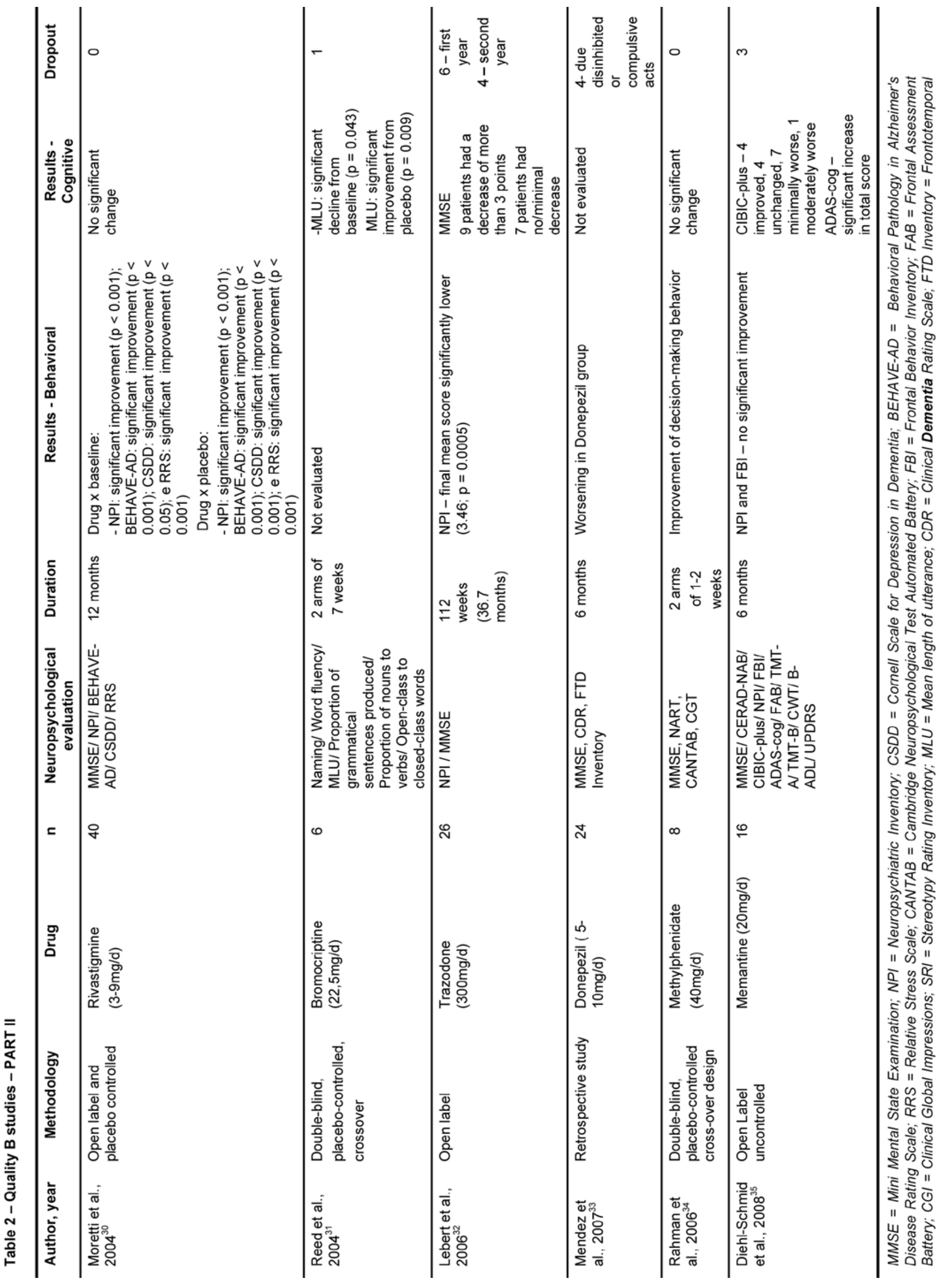




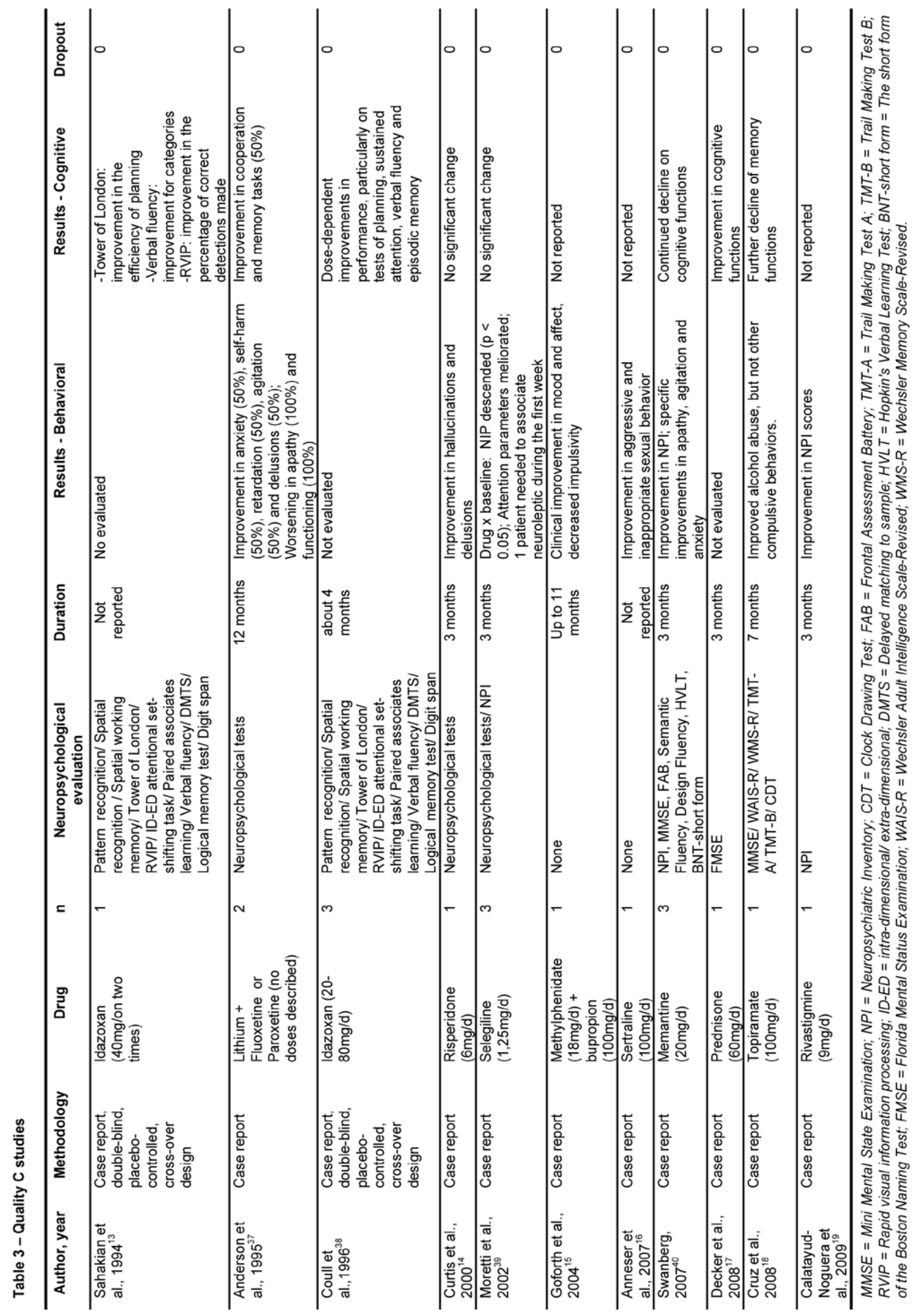


another study, Kertesz et al., in $2008,{ }^{25}$ did not note any significant change using Galantamine for FTLD.

Four quality B studies reported a significant improvement in behavior with Trazodone or Fluvoxamine or Rivastigmine. ${ }^{27,29,30,32}$ Four quality B studies noted behavioral improvement without significant results, ${ }^{12,28,34,36}$ two studies did not observe any significant behavioral change, ${ }^{26,36}$ one study described behavioral worsening ${ }^{33}$ and one study did not assess this aspect. ${ }^{31}$

On the other hand, there were conflicting results from the studies that focused on the efficacy of treatment for cognitive impairment. Seven quality B studies did not reveal any significant changes..$^{26-28,30,32,34}$ However, the Bromocriptine study showed a significant improvement in the mean time of utterance as compared to the placebo, ${ }^{31}$ and one Memantine study found a significant increase in the total score of ADAS-Cog. ${ }^{35}$ In 2009, Boxer et al. noted decline on most of the cognitive measures with Memantine. ${ }^{36}$ Two B studies did not evaluate cognitive functions. ${ }^{12,33}$

The quality $\mathrm{C}$ studies showed a significant improvement in behavior with Selegiline. ${ }^{37}$ Another seven studies noted improvement in behavior although not statistically significant. ${ }^{14-16,18,19,38,39}$ As for efficacy in cognition, two studies showed no change, ${ }^{14,37}$ whereas four others reported a clinical improvement, also not statistically significant. ${ }^{13,17,38,40}$

Overall, we found that $1 / 3$ of the studies reported significant improvement in behavior symptoms with SSRI, 1/3 showed clinical but not statistically significant changes and $1 / 6$ showed no differences from baseline evaluation. Also, 1/6 observed clinical improvement in anxiety, self-harm, retardation, agitation and delusions, but also observed worsening in apathy and functioning although this was not statistically significant. There was a significant cognitive impairment in $1 / 6$ of the studies, a clinically relevant but not statistically significant improvement in $1 / 6$ and no difference from baseline observation in another $1 / 3$ of the studies. It is worth noting that $1 / 6$ of the studies observed significant worsening.

The prescribed doses followed the general recommendations of the clinical practice, although two studies did not say what dosage was used. ${ }^{12,38}$ The duration of the trials varied from four to 112 weeks $^{2,8,32}$ though two studies did not report the length of treatment. ${ }^{13,16}$ The dropout rate was less than or equal to $18.75 \%$, except for one Paroxetine study and one Trazodone study which showed a $40 \%$ and $38.46 \%$ dropout rate respectively. ${ }^{21,32}$ Only one study did not report the dropout rate. ${ }^{12}$ Most dropouts occurred due to agitation and other symptoms related to the disease, although random reasons such as dehydration, a traffic accident, and moderate fever with urinary infection may also have been a consequence of difficult management of FTLD.

\section{Discussion}

The number of randomized studies retrieved and the mean sample found could be considered small if compared with the usual number recruited in general dementia studies. However, this sample rate may be explained by the low prevalence of FTLD in the community, as well as by difficulties in diagnosing and in differential diagnosis of this disorder. Also, the lack of uniformity in FTLD diagnostic criteria precludes the generalization of the results. ${ }^{41}$ Approximately one-third of the sample studied did not have a clear description of the FTLD subtype evaluated. On the other hand, the analysis of behavioral symptoms as the outcome of treatment in FTLD showed that only six studies presented relevant data on this issue. All these studies report only positive data, and it is not possible to draw a generalized conclusion form the studies.

CT and MRI usually yield normal results at the early stages of FTLD, and the focal atrophy of temporal and frontal lobes appear at the moderate to severe clinical stages; ${ }^{42}$ SPECT is a useful diagnostic instrument in the early stages, when structural changes are not yet evident. The changes in frontal and in temporal blood flow grow more marked as the disease progresses ${ }^{43-45}$ providing information for diagnosing it in $90 \%$ of cases, especially if they are correlated with clinical parameters. ${ }^{46}$ Therefore, there were also some difficulties posed by the neuroimaging and neuropsychological examinations described in the studies which also precluded the combined evaluation of data.

The combination of the Mini-mental state examination (MMSE) with another instrument was the most frequently used method of cognitive assessment. It is worth noting, however, that there are some flaws in using MMSE as a cognitive screening test in FTLD because the patient usually scores within the normal range (28-30 points) for a long time throughout the disease process. Language and executive functions are the most impaired domains in FTLD, and MMSE is not a suitable instrument to evaluate these functions. ${ }^{47}$ Other screening tests, such as the Clock Drawing and the Verbal Fluency tests (semantic categories) can provide more valuable information on the cognitive impairment related to fronto-temporal disorders.

This study yielded nine trials which evaluated drugs with a serotonergic action, six with SSRIs and three with Trazodone. This treatment choice is based on the observation of efficacy in other behavior symptoms and in affective states which occur in psychiatric disorders. ${ }^{26}$ Also, this beneficial effect might be explained by recent studies which showed a decrease in serotonin in the temporal and frontal cortex in FTLD patients. ${ }^{48}$ Paroxetine was studied twice. Both quality A trials revealed a significant cognitive impairment, whereas one study showed a significant behavior improvement. ${ }^{20,21}$ Paroxetine was also studied, in a quality $\mathrm{C}$ report, in which the combination with lithium carbonate did not show any significant result. The same negative result was reported for the combination of Fluoxetine and lithium carbonate. ${ }^{38}$ Fluvoxamine (quality B trial) showed a significant improvement in behavior, ${ }^{29}$ whereas the trial with three other SSRIs ${ }^{26}$ showed no significant cognitive or behavior changes. Sertraline was evaluated in one case report and produced improvement in aggressive and inappropriate sexual behavior, but without statistical significance. ${ }^{16}$ Pijnenburg et al.'s study $(2003)^{12}$ did not mention which antidepressive drug was used. 
Trazodone has demonstrated efficacy for behavior symptoms in Alzheimer's Disease, ${ }^{21}$ possibly because of its serotonergic action. Trazodone is an atypical serotonergic agent with a post-synaptic antagonism on $5 \mathrm{HTA} / 2 \mathrm{c}$ receptors and an agonist effect on 5 HT1a receptors. The three Trazodone studies (quality A and B) showed a significant improvement in behavior but not in cognitive symptoms. $^{23,27,32}$

The use of dopaminergic drugs in FTLD is controversial. Dopaminergic blockers can occasionally control some behavior disturbances in FTLD but it is also conceivable that patients with apathy and lack of motivation may benefit from the use of selective dopamine agonists. ${ }^{10}$ Risperidone was evaluated in one quality $\mathrm{C}$ study and did not reveal any change in cognitive or behavior symptoms. ${ }^{14}$ Bromocriptine yielded a significant cognitive improvement as compared to placebo and a significant cognitive worsening as compared to baseline observations in a quality B study. ${ }^{31}$ As many FTLD patients present with agitation and psychosis, there is a rather intuitive move by the clinical psychiatrist to choose neuroleptics as a first-line treatment. Counterintuitive as this may appear to be, there seem to be more data favoring the use of SSRIs (a serotonergic strategy) than the use of neuroleptics. Furthermore, the use of neuroleptics should be discussed with care since there have been concerns that they may be involved in a higher risk of cerebrovascular accidents in elderly people with dementia. ${ }^{49,50}$

FTLD is definitely not a hypocholinergic dementia. ${ }^{30}$ This might explain why anticholinesterasics did not have significant therapeutic action in three studies ${ }^{25,33,51}$ although one quality $\mathrm{B}$ study found significantly improved behavior ${ }^{30}$ and one quality $\mathrm{A}$ study found cognitive improvement in FTLD. ${ }^{22}$

Idazoxan is an alfa-2-adrenergic antagonist which can modulate noradrenaline function in the frontal lobe. ${ }^{40}$ This drug was evaluated in two quality $\mathrm{C}$ studies and showed cognitive improvement without statistical significance. ${ }^{13,40}$ Behavior was not analyzed in these studies.

$A$ and $B$ monoamine oxidase inhibitors may have a neuroprotective effect by reducing oxidative free radicals, ${ }^{52}$ and they might be useful in FTLD, given the serotonergic and dopaminergic deficits which are common in this type of dementia. Moclobemide was used in a quality B study but there was no significant cognitive or behavior change with the drug. ${ }^{28}$ Selegiline (a quality C study) showed a significant improvement in behavior but no effect on cognition. ${ }^{37}$

Yeaworth \& Burke (2000) suggested that benzodiazepines, sodium divalproate and antipsychotics may be useful to control behavioral symptoms in FTLD. ${ }^{1}$ We found one study with risperidone but none with benzodiazepines or sodium divalproate which could meet the requirements for inclusion in this review.

This study presents some limitations that deserve to be commented upon. It was not possible to perform any combined analysis of the results because of the heterogeneity of instruments and of the efficacy measures used in the different studies.

This review shows that there is an insufficient body of evidence to conclude what is the best treatment for FTLD, and that more studies with proper design are still needed. SSRIs are the most widely-used drugs for the management of behavior symptoms in FTLD, although none of the distinct classes of compounds have demonstrated consistent evidence of response on the cognitive and behavior aspects of FTLD. Although one might consider that there is still a dearth of data on evidence-based strategies to rely upon to treat FTLD, clinical practice using SSRIs in the first place seems to be the best prescription at the present moment to treat behavioral symptoms. Some cases may also respond to low doses of antipsychotics, although caution should be exercised in view of the possible side effects.

\section{Conflict of interest}

Maria da Glória Portugal has no conflict to declare. Valeska Marinho is medical manager of GlaxoSmithKline. Jerson Laks has been a lecturer, and worked as a consultant and in clinical trials with Apsen, Eli Lilly, GlaxoSmithKline, Janssen-Cilag, Novartis, and Wyeth-Whitehall.

\section{Description of author's roles}

Maria da Glória Portugal, Valeska Marinho, and Jerson Laks designed the study and wrote the text. Maria da Glória Portugal collected and organized the data, and analyzed the data together with Valeska Marinho. All the authors contributed to the final writing of the report/text.

\section{Acknowledgements}

The authors would like to acknowledge the contribution of Luzinete N.O. Alvarenga in providing editorial assistance and the support offered by the National Research Board (Conselho Nacional de Desenvolvimento Científico e Tecnológico, CNPq). 


\section{Disclosures}

\begin{tabular}{|c|c|c|c|c|c|c|c|}
\hline $\begin{array}{l}\text { Writing group } \\
\text { member }\end{array}$ & Employment & $\begin{array}{l}\text { Research } \\
\text { grant }^{1}\end{array}$ & $\begin{array}{c}\text { Other research grant } \\
\text { or medical continuous } \\
\text { education }{ }^{2}\end{array}$ & $\begin{array}{l}\text { Speaker's } \\
\text { honoraria }\end{array}$ & $\begin{array}{c}\text { Ownership } \\
\text { interest }\end{array}$ & $\begin{array}{c}\text { Consultant/ } \\
\text { Advisory } \\
\text { board }\end{array}$ & Other ${ }^{3}$ \\
\hline $\begin{array}{l}\text { Maria da Glória } \\
\text { Portugal }\end{array}$ & UFRJ & - & - & - & - & - & - \\
\hline Valeska Marinho & GSK & - & - & - & - & - & - \\
\hline Jerson Laks & $\begin{array}{l}\text { UFRJ } \\
\text { UERJ }\end{array}$ & $\begin{array}{l}\text { CNPq }^{* * *} \\
\text { FAPERJ*** }^{*}\end{array}$ & Novartis ${ }^{* * *}$ & 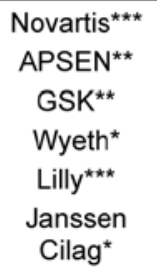 & - & $\begin{array}{c}\text { GSK } \\
\text { Lilly } \\
\text { Novartis }\end{array}$ & - \\
\hline
\end{tabular}

${ }^{*}$ Modest

** Significant

*** Significant: Amounts given to the author's institution or to a colleague for research in which the author has participation, not directly to the au Note: UFRJ = Universidade Federal do Rio de Janeiro; GSK = GlaxoSmithKline; UERJ = Universidade do Estado do Rio de Janeiro; CNPq = Conselho Nacional de Desenvolvimento Científico e Tecnológico; FAPERJ = Fundação de Amparo à Pesquisa do Estado do Rio de Janeiro. For more information, see Instructions for Authors.

\section{References}

1. Yeaworth RC, Burke WJ. Frontotemporal dementia: a different kind of dementia. Arch Psychiatr Nurs. 2000;14(5):249-53.

2. Herrera E Jr, Caramelli P, Silveira AS, Nitrini R. Epidemiologic survey of dementia in a community-dwelling Brazilian population. Alzheimer Dis Assoc Disord. 2002;16(2):103-8.

3. Ratnavalli E, Brayne C, Dawson K, Hodges JR. The prevalence of frontotemporal dementia. Neurology. 2002;58(11):1615-21

4. Rosso SM, Donker Kaat L, Baks T, Joosse M, de Koning I, Pijnenburg Y, de Jong D, Dooijes D, Kamphorst W, Ravid R, Niermeijer MF, Verheij F, Kremer HP, Scheltens P, van Duijn CM, Heutink P, van Swieten JC. Frontotemporal dementia in The Netherlands: patient characteristics and prevalence estimates from a population-based study. Brain. 2003;126(Pt 9):2016-22.

5. Ikeda M, Ishikawa T, Tanabe H. Epidemiology of frontotemporal lobar degeneration. Dement Geriatr Cogn Disord. 2004;17(4):265-8.

6. Rabinovici GD, Miller BL. Frontotemporal lobar degeneration: epidemiology, pathophysiology, diagnosis and management. CNS Drugs. 2010;24(5):375-98.

7. The Lund and Manchester Groups. Clinical and neuropathological criteria for frontotemporal dementia. J Neurol Neurosurg Psychiatry. 1994;57(4):416-8.

8. Neary D, Snowden JS, Gustafson L, Passant U, Stuss D, Black S, Freedman M, Kertesz A, Robert PH, Albert M, Boone K, Miller BL, Cummings J, Benson DF. Frontotemporal lobar degeneration: a consensus on clinical diagnostic criteria. Neurology. 1998;51(6):1546-54.

9. Litvan I, Agid Y, Sastrj N, Jankovic J, Wenning GK, Goetz CG, Verny M, Brandel JP, Jellinger K, Chaudhuri K, McKee A, Lai EC, Pearce RKB, Bartko JJ. What are the obstacles for the accurate diagnosis of Pick's disease? A clinicopathologic study. Neurology. 1997;49(1):62-9.

10. Litvan I. Therapy and management of frontal lobe dementia patients. Neurology. 2001;56(Suppl 4):S41-5.

11. Furlan AD, Pennick V, Bombardier C, Van Tulder M, Cochrane Back Review Group [editorial]. 2009 Updated method guidelines for systematic reviews in the cochrane back review group. Spine. 34(18):1929-41.

12. Pijnenburg YA, Sampson EL, Harvey RJ, Fox NC, Rossor MN. Vulnerability to neuroleptic side effects in frontotemporal lobar degeneration. Int $J$ Geriatr Psychiatry. 2003;18(1):67-72.

13. Sahakian BJ, Coull JJ, Hodges JR. Selective enhancement of executive function by Idazoxan in a patient with dementia of the frontal lobe type. J Neurol Neurosurg Psychiatry. 1994;57(1):120-1.

14. Curtis RC, Resch DS. Case of Pick's central lobar atrophy with apparent stabilization of cognitive decline after treatment with risperidone. J Clin Psychopharmacol. 2000;20(3):384-5.

15. Goforth HW, Konopka L, Primeau M, Ruth A, O'donnell K, Patel R, Poprawski T, Shirazi P, Rao M. Quantitative electroencephalography in frontotemporal dementia with methylphenidate response: a case study. Clin EEG Neurosci. 2004;35(2):108-11.

16. Anneser JMH, Jox RJ, Borasio GD. Inappropriate sexual behavior in a case of ALS and FTD: successful treatment with sertraline. Amyotroph Lateral Scler. 2007;8(3):189-90.

17. Decker DA, Heilman KM. Steroid treatment of primary progressive aphasia. Arch Neurol. 2008;65(11):1533-5.

18. Cruz M, Marinho V, Fontenelle LF, Engelhardt E, Laks J. Topiramate may modulate alcohol abuse but not other compulsive behaviors in frontotemporal dementia: case report. Cogn Behav Neurol. 2008;21(2):104-6.

19. Calatayud-Noguera T, Aastudillo-González A, Alvarez-Carriles JC, TempranoFernández T, Cortés-Velarde M, Oliva-Nacarino P. Rivastigmine in a case of autopsy proved frontotemporal dementia (Pick's disease). Rev Neurol. 2009; $48(11): 582-4$.

20. Moretti R, Torre P, Antonello RM, Cazzato G, Bava A. Frontotemporal dementia: paroxetine as a possible treatment of behavior symptoms. Eur Neurol. 2003;49(1):13-9.

21. Deakin JB, Rahman S, Nestor PJ, Hodges JR, Sahakian BJ. Paroxetine does not improve symptoms and impairs cognition in frontotemporal dementia: a double-blind randomized controlled trial. Psychopharmacology. 2004;172(4):400-8.

22. Lampl Y, Sadeh M, Lorberboym M. Efficacy of acetylcholinesterase inhibitors in frontotemporal dementia. Ann Pharmacother. 2004;38(11):1967-8.

23. Lebert F, Sstekke W, Hasenbroeky C, Pasquier F. Frontotemporal dementia: a randomised, controlled trial with trazodone. Dement Geriatr Cogn Disord. 2004;17(4):355-9.

24. Huey ED, Garcia C, Wassermann EM, Tierney MA, Grafman J. Stimulant treatment of frontotemporal dementia in 8 patients. J Clin Psychiatry. 2008;69(12):1981-2.

25. Kertesz A, Morlog D, Light M, Blair M, Davidson W, Jesso S, Brashear R. Galantamine in frontotemporal dementia and primary progressive aphasia. Dement Geriatr Cogn Disord. 2008;25(2):178-85.

26. Swartz JR, Miller BL, Lesser IM, Darby AL. Frontotemporal dementia: treatment response to serotonin selective reuptake inhibitors. J Clin Psychiatry. 1997;58(5):212-6.

27. Lebert F, Pasquier F. Trazodone in the treatment of behaviour in frontotemporal dementia. Hum Psychopharmacol Clin Exp. 1999;14(4):279-81.

28. Adler G, Teufel M, Drach LM. Pharmacological treatment of frontotemporal dementia: treatment response to the MAO-A inhibitor moclobemide. Int J Geriatr Psychiatry. 2003;18(7):653-5.

29. Ikeda M, Shigenobu K, Fukuhara R, Hokoishi K, Maki N, Nebu A, Komori $\mathrm{K}$, Tanabe H. Efficacy of fluvoxamine as a treatment for behavioral symptoms in frontotemporal lobar degeneration patients. Dement Geriatr Cogn Disord. 2004;17(3):117-21. 
30. Moretti R, Torre P, Antonello RM, Cataruzza T, Cazzato G, Bava A. Rivastigmine in frontotemporal dementia: an open-label study. Drugs Aging. 2004;21(14):931-7.

31. Reed DA, Johnson NA, Thompson C, Weintraub S, Mesulam MM. A clinical trial of bromocriptine for treatment of primary progressive aphasia. Ann Neurol. 2004;56(5):750.

32. Lebert F. Behavioral benefits of trazodone are sustained for the long term in frontotemporal dementia. Therapy. 2006;3(1):93-6.

33. Mendez MF, Shapira JS, Mcmurtray A, Licht E. Preliminary findings: behavioral worsening on donepezil in patients with frontotemporal dementia. Am J Geriatr Psychiatry. 2007;15(1):84-7.

34. Rahman S, Robbins TW, Hodges JR, Mehta MA, Nestor PJ, Clark L, Sahakian BJ. Methylphenidate ('Ritalin') can ameliorate abnormal risktaking behaviour in the frontal variant of frontotemporal dementia. Neuropsychopharmacology. 2006;31(3):651-8.

35. Diehl-Schmid J, Förstl H, Perneczky R, Pohl C, Kurz A. A 6-month, openlabel study of memantine in patients with frontotemporal dementia. Int J Geriatr Psychiatry. 2008;23(7):754-9.

36. Boxer AL, Lipton AM, Womack K, Merrilees J, Neuhaus J, Pavlic D, Gandhi A, Red D, Martin-Cook K, Svetlik D, Miller BL. An open-label study of memantine treatment in 3 subtypes of frontotemporal lobar degeneration. Alzheimer Dis Assoc Disord. 2009;23(3):211-7.

37. Moretti R, Torre P, Antonello RM, Cazzato G, Bava A. Effects of selegiline on fronto-temporal dementia: a neuropsychological evaluation. Int J Geriatr Psychiatry. 2002;17(4):391-2.

38. Anderson IM, Scott K, Harborne G. Serotonine and depression in frontal lobe dementia. Am J Psychiatry. 1995;152(4):645.

39. Swanberg MM. Memantine for behavioral disturbances in frontotemporal dementia: a case series. Alzheimer Dis Assoc Disord. 2007;21(2):164-6.

40. Coull JJ, Sahakian BJ, Hodges JR. The alpha(2) antagonist idazoxan remediates certain attentional and executive dysfunction in patients with dementia of frontal type. Psychopharmacology. 1996;123(3):239-49.

41. Pasquier F, Fukui T, Sarazin M, Pijnenburg Y, Diehl J, Grundman M, Miller BL. Laboratory investigations and treatment in frontotemporal dementia. Ann Neurol. 2003;54(Suppl 5):S32-5.

42. Cummings JL. Neuropsychiatric aspects of Alzheimer's disease and other dementing illnesses. In: Yudofsky SC, Hales RE, editors. The American psychiatric press textbook of neuropsychiatry. 2nd ed. Washington DC: American Psychiatric Press; 1992. p.605-20.

43. Miller BL, Cummings JL, Villanueva-Meyer J, Boone K, Mehringer CM, Lesser IM, Mena I. Frontal lobe degeneration: clinical, neuropsychological, and SPECT characteristics. Neurology. 1991; 41 (9):1374-82.

44. Risberg J. Frontal lobe degeneration of non-Alzheimer type, III: regional cerebral blood flow. Arch Gerontol Geriatr. 1987;6(3):225-33.

45. Risberg J, Passant U, Warkentin S, Gustafson L. Regional cerebral blood flow in frontal lobe dementia of non-Alzheimer type. Dementia. 1993;4(34):186-7.

46. Read SL, Miller BL, Mena I, Kim R, Itabashi H, Darby A. SPECT in dementia: clinical and pathological correlation. J Am Geriatr Soc. 1995;43(11):1243-7.

47. Pasquier F, Richard F, Lebert F. Natural history of frontotemporal dementia: comparison with Alzheimer's disease. Dement Geriatr Cogn Disord. 2004;17(4):253-7.

48. Perry RJ, Miller BL. Behavior and treatment in frontotemporal dementia. Neurology. 2001;56(Suppl 4):S46-51.

49. Wooltorton E. Risperidone (Risperdal): increased rate of cerebrovascular events in dementia trials. CMAJ. 2002;167(11):1269-70.

50. Wooltorton E. Olanzapine (Zyprexa): increased incidence of cerebrovascular events in dementia trials. CMAJ. 2004;170(9):1395.

51. Diehl J, Kurz A. Frontotemporal dementia. Wien Med Wochenschr. 2002;152(34):92-7.

52. Alafuzoff I, Helishami S, Heinonen EH, Reinikainen K, Hallikainen M, Soininen H, Koivisto K. Selegiline treatment and extent of degenerative changes in brain tissue of patients with Alzheimer's disease. Eur J Clin Pharmacol. 2000;55(11-12):815-9. 